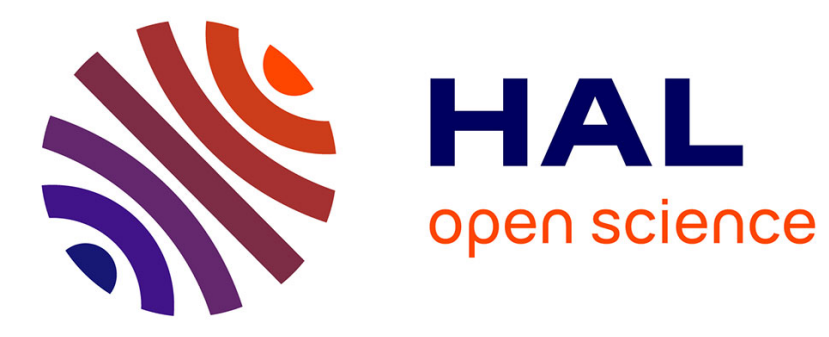

\title{
DUV LEDs based on AlGaN quantum dots
}

Julien Brault, Mohamed Al Khalfioui, Mathieu Leroux, Samuel Matta, Thi-Huong Ngo, Aly Zaiter, Aimeric Courville, Benjamin Damilano, Sébastien Chenot, Jean-Yves Duboz, et al.

\section{- To cite this version:}

Julien Brault, Mohamed Al Khalfioui, Mathieu Leroux, Samuel Matta, Thi-Huong Ngo, et al.. DUV LEDs based on AlGaN quantum dots. SPIE OPTO, Mar 2021, Online Only, United States. pp.16, $10.1117 / 12.2576135$. hal-03366593

\section{HAL Id: hal-03366593 https://hal.science/hal-03366593}

Submitted on 5 Oct 2021

HAL is a multi-disciplinary open access archive for the deposit and dissemination of scientific research documents, whether they are published or not. The documents may come from teaching and research institutions in France or abroad, or from public or private research centers.
L'archive ouverte pluridisciplinaire HAL, est destinée au dépôt et à la diffusion de documents scientifiques de niveau recherche, publiés ou non, émanant des établissements d'enseignement et de recherche français ou étrangers, des laboratoires publics ou privés. 


\title{
DUV LEDs based on AIGaN Quantum Dots
}

\author{
Julien Brault*a, Mohamed Al Khalfioui ${ }^{\mathrm{a}}$, Mathieu Leroux ${ }^{\mathrm{a}}$, Samuel Matta ${ }^{\mathrm{a}, \mathrm{b}, \mathrm{c}}$, Thi-Huong Ngo ${ }^{\mathrm{b}}$, Aly \\ Zaiter $^{\mathrm{a}}$, Aimeric Courville ${ }^{\mathrm{a}}$, Benjamin Damilano ${ }^{\mathrm{a}}$, Sébastien Chenot ${ }^{\mathrm{a}}$, Jean-Yves Duboz ${ }^{\mathrm{a}}$, Jean \\ Massies $^{\mathrm{a}}, \mathrm{P}$. Valvin $^{\mathrm{b}}$, Bernard Gil $^{\mathrm{b}}$ \\ âniversité Côte d'Azur, CNRS, CRHEA, Rue Bernard Grégory, CS 10269, 06905 Sophia \\ Antipolis Cedex France; ${ }^{b}$ CNRS-Université Montpellier 2, Laboratoire Charles Coulomb and

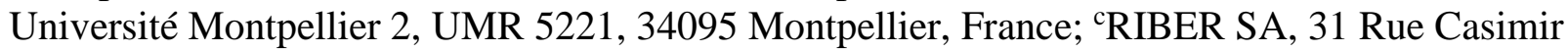 \\ Périer, 95870 Bezons
}

\begin{abstract}
Deep ultra-violet (DUV) light emitting diodes (LED) are expected to be the next generation of UV sources, offering significant advantages such as compactness, low consumption and long lifetimes. Yet, improvements of their performances are still required and the potential of $\mathrm{Al}_{\mathrm{y}} \mathrm{Ga}_{1-\mathrm{y}} \mathrm{N}$ quantum dots as DUV emitters is investigated in this study. Using a stress induced growth mode transition, quantum dots (QD) are spontaneously formed on $\mathrm{Al}_{0.7} \mathrm{Ga}_{0.3} \mathrm{~N} / \mathrm{AlN}$ heterostructures grown on sapphire substrates by molecular beam epitaxy. By increasing the QD Al composition, a large shift of the QD photoluminescence in the UV range is observed, going from an emission in the near UV for GaN QD down to the UVC region for $\mathrm{Al}_{0.4} \mathrm{Ga}_{0.6} \mathrm{~N}$ QD. A similar behavior is observed for electroluminescence (EL) measurements performed on LED structures and an emission ranging from the UVA (320-340 nm) down to the UVC (265-280 nm) has been obtained. The main performances of $\mathrm{Al}_{0.7} \mathrm{Ga}_{0.3} \mathrm{~N}$ based QD LED are presented in terms of electrical and optical characteristics. In particular, the emission dependence on the input current density, including the emitted wavelength, the optical power and the external quantum efficiency are shown and discussed.
\end{abstract}

Keywords: Nitride semiconductors, LED, AlGaN, Deep UV, Molecular Beam Epitaxy, Quantum Dots, External Quantum Efficiency.

\section{INTRODUCTION}

$\mathrm{Al}_{\mathrm{y}} \mathrm{Ga}_{1-\mathrm{y}} \mathrm{N}$ quantum dots (QD) are attractive as ultra-violet (UV) emitters for the fabrication of deep ultra-violet (DUV) light emitting diodes (LED). Due to their dimensions in the nanometer range, $\mathrm{Al}_{\mathrm{y}} \mathrm{Ga}_{1-\mathrm{y}} \mathrm{N}$ QD are used to confine electrons and holes in the LED active region along the three directions of space and consequently favor the radiative recombination of excitons. ${ }^{1}$ This property is particularly attractive in the case of materials and heterostructures containing very high defect densities. ${ }^{2,3}$ Such a situation occurs in our approach which is based on the use of thin $\mathrm{Al}_{x} \mathrm{Ga}_{1}$. ${ }_{x} \mathrm{~N} /$ AlN structures $(<1 \mu \mathrm{m})$ monolithically grown on sapphire by molecular beam epitaxy (MBE) focusing on simple LED designs and low-cost fabrication processes. As a consequence, the threading dislocation densities (TDD) are above $10^{10} \mathrm{~cm}^{-2}$ in our LED active regions. ${ }^{4,5}$ These very high TDD would be detrimental for the LED performances in terms of internal quantum efficiencies (IQE) which have been measured to be well below $1 \%$ in the case of $\mathrm{Al}_{\mathrm{y}} \mathrm{Ga}_{1-\mathrm{y}} \mathrm{N} / \mathrm{Al}_{\mathrm{x}} \mathrm{Ga}_{1-\mathrm{x}} \mathrm{N}$ quantum wells $(\mathrm{QW}){ }^{6}{ }^{6}$ The situation is quite different in the case of $\mathrm{Al}_{\mathrm{y}} \mathrm{Ga}_{1-\mathrm{y}} \mathrm{N}$ QD since temperature dependent photoluminescence $(\mathrm{PL})$ measurements have shown a weak decrease of the integrated PL intensity from cryogenic temperatures up to room temperature of one order of magnitude or less, ${ }^{7,8}$ compared to more than two order of magnitude in the case of QW. ${ }^{10,11}$ In addition, using specific growth conditions and/or surface orientations, a further improved integrated PL intensity can be obtained by tailoring the QD shape, ${ }^{9,12,13}$ which can also be combined with a modification of the wavelength emission. ${ }^{14,15,16}$

The MBE grown $\mathrm{Al}_{y} \mathrm{Ga}_{1-\mathrm{y}} \mathrm{N}$ QD are spontaneously formed using a Stranski-Krastanov growth mode where a transition from a 2 dimensional (D) to a 3D layer occurs after the deposition of an amount above a critical thickness $\left(\mathrm{h}_{2 \mathrm{D}-3 \mathrm{D}) .}{ }^{17} \mathrm{This}\right.$ specific growth is obtained by taking advantage of the epitaxial stress between $\mathrm{Al}_{y} \mathrm{Ga}_{1-y} \mathrm{~N}$ layer and the $\mathrm{Al}_{\mathrm{x}} \mathrm{Ga}_{1-\mathrm{x}} \mathrm{N}$ cladding layer (with $\mathrm{x}>\mathrm{y}$ ) and the 3D growth is characterized by the formation of nanometer-sized 3D islands with lateral dimensions in the $10 \mathrm{~nm}$ range and heights in the nm range. ${ }^{9,18}$

* Julien.Brault@crhea.cnrs.fr phone +33.4.93.95.41.08 (41.98); http://www.crhea.cnrs.fr/en/personal-pages/page-jb.asp 
$\mathrm{Al}_{\mathrm{x}} \mathrm{Ga}_{1-\mathrm{x}} \mathrm{N}$ LED emitting in the UVB (280-320 $\mathrm{nm}$ ) and in the UVC (below $280 \mathrm{~nm}$ ) ranges are seen as the next UV technology for medical (e.g. dermatology) and environmental (e.g. water and air purification) applications in replacement of mercury-based lamps which uses are being progressively banned. An intense research activity ${ }^{19}$ aims at improving their efficiencies which are still limited to external quantum efficiencies (EQE) of a few percents. Higher internal, injection and/or extraction efficiencies are targeted by developing a wide panel of materials and/or technological approaches (e.g. bulk AlN substrates, high temperature annealing, tunnel junctions, polarization induced doping, BN and alloys, etc.). ${ }^{20}$

In this study, we focus on the properties of $\mathrm{Al}_{y} \mathrm{Ga}_{1-\mathrm{y}} \mathrm{N}$ QD with y ranging from $10 \%$ to $40 \%$ embedded in $\mathrm{Al}_{x} \mathrm{Ga}_{1-\mathrm{x}} \mathrm{N}$ cladding layers with $\mathrm{x}$ equals to $70 \%$, and discuss their potential as active regions for deep UV LED. The self-assembled $\mathrm{Al}_{\mathrm{y}} \mathrm{Ga}_{1-\mathrm{y}} \mathrm{N}$ QD have very high surface densities in the $10^{11} \mathrm{~cm}^{-2}$ range, lateral dimensions ranging between 5-15 $\mathrm{nm}$ and heights between 1.5-2.5 $\mathrm{nm}$. By varying the $\mathrm{Al}$ concentration, photoluminescence spectra show an emission in a broad range from UVA to UVC regions. LED structures made of three to five $\mathrm{Al}_{y} \mathrm{Ga}_{1-y} \mathrm{~N}$ QD planes have been grown by MBE. Current - voltage measurements have been performed along with an in-depth investigation of the LED emission characteristics as a function of the current density. LEDs emitting in the UVB and UVC regions have been fabricated and the main electro-optical characteristics (optical power, external quantum efficiency) of QD based LED are presented. The remaining issues to reach higher EQE and ways to solve them are briefly discussed to conclude the study.

\section{METHODOLOGY}

The heterostructures have been fabricated by MBE (in a RIBER 32 reactor) on AlN buffer layers (BL) grown on c-plane sapphire substrates. Ammonia $\left(\mathrm{NH}_{3}\right)$ was used as the nitrogen source together with solid sources for $\mathrm{Ga}, \mathrm{Al}, \mathrm{Si}$ and $\mathrm{Mg}$. However, for the $\mathrm{Al}_{\mathrm{y}} \mathrm{Ga}_{1-\mathrm{y}} \mathrm{N}$ QD fabrication step, a RF plasma cell with nitrogen $\left(\mathrm{N}_{2}\right)$ gas was used instead of $\mathrm{NH}_{3}$. Sapphire is well adapted to the fabrication of LED in the UV due to its transparency in this spectral region that spans beyond the AlN band gap (i.e. $\lambda \approx 206 \mathrm{~nm}$ at room temperature). The AlN buffer is grown in a two step process: at first, a nucleation layer of $3 \mathrm{~nm}$ is deposited at $500^{\circ} \mathrm{C}$ and then, a $130 \mathrm{~nm}$ thick layer is grown at $1000^{\circ} \mathrm{C}$, following the conditions detailed in ref. 4. Next, a $700 \mathrm{~nm}$ thick Si-doped $\mathrm{Al}_{0.7} \mathrm{Ga}_{0.3} \mathrm{~N}$ layer is deposited at $870^{\circ} \mathrm{C}$, with a $\mathrm{Si}$ concentration around $10^{19} \mathrm{~cm}^{-3}$, followed by the LED active region made of $\mathrm{Al}_{\mathrm{y}} \mathrm{Ga}_{1-\mathrm{y}} \mathrm{N}$ QD planes separated by $\mathrm{Al}_{0.7} \mathrm{Ga}_{0.3} \mathrm{~N}$ cladding layers. In this study, LED structures (see Figure 3(a) - following a structure design similar to the ones described in refs. 11,21,22) with different $\mathrm{Al}$ concentrations for the $\mathrm{Al}_{\mathrm{y}} \mathrm{Ga}_{1-\mathrm{y}} \mathrm{N}$ QD (i.e. with $\mathrm{y}=0.1,0.2,0.3$ or $0.4)$ were investigated. The QD fabrication process involved a post-growth annealing step after the deposition of an $\mathrm{Al}_{y} \mathrm{Ga}_{1-\mathrm{y}} \mathrm{N}$ amount of $2 \mathrm{~nm}$, in order to improve the QD shape and size uniformity and avoid the formation of elongated QD ${ }^{9,12,14,22}$ Then, a $10 \mathrm{~nm}$ thick $\mathrm{Mg}$-doped $\mathrm{Al}_{0.8} \mathrm{Ga}_{0.2} \mathrm{~N}$ electron blocking layer and a $10 \mathrm{~nm}$ thick $\mathrm{Mg}$-doped $\mathrm{Al}_{0.7} \mathrm{Ga}_{0.3} \mathrm{~N}$ layer are grown at $820^{\circ} \mathrm{C}$ and the structure is ended with a $30 \mathrm{~nm}$ thick Mg-doped $\mathrm{GaN}$ contact layer at a temperature of $780^{\circ} \mathrm{C}$, with a $\mathrm{Mg}$ concentration around $5 \times 10^{19}-1 \times 10^{20} \mathrm{~cm}^{-3}$. Reference samples made of one QD plane buried in an $\mathrm{Al}_{0.7} \mathrm{Ga}_{0.3} \mathrm{~N}$ cladding layer for PL measurements and a surface QD plane for AFM observations (performed in tapping mode) have also been studied.

For the different $\mathrm{Al}_{\mathrm{y}} \mathrm{Ga}_{1-\mathrm{y}} \mathrm{N}$ QD active region structures, LED with a squared geometry were fabricated in clean room by using photolithography and electron cyclotron resonance reactive ion etching processes. The LED mesas, with a size of 310 × $310 \mu \mathrm{m}^{2}$, are covered by a thin $\mathrm{Ni} / \mathrm{Au}(5 / 5 \mathrm{~nm})$ semi-transparent current spreading layer plus a $\mathrm{Ni} / \mathrm{Au}(20 / 200$ $\mathrm{nm}$ ) contact as top electrode to $\mathrm{p}-\mathrm{GaN}$. The contact on $\mathrm{n}-\mathrm{Al}_{0.7} \mathrm{Ga}_{0.3} \mathrm{~N}$ is a stacking of $\mathrm{Ti} / \mathrm{Al} / \mathrm{Ni} / \mathrm{Au}(30 / 180 / 40 / 200$ $\mathrm{nm})$. The LED were studied at room temperature by measuring the current - voltage (I-V) and electroluminescence (EL) characteristics. The EL was measured from the sapphire side of the LED by collecting the light in an UV-grade optical fiber connected to a linear CCD spectrometer with a spectral resolution of $2.5 \mathrm{~nm}$. The optical power $\left(\mathrm{P}_{\mathrm{opt}}\right)$ was also measured from the backside of the devices placed on top of a calibrated UV enhanced Si photodiode.

\section{RESULTS}

Typical atomic force microscopy (AFM) images of reference samples including an AlN BL, an $\mathrm{Al}_{0.7} \mathrm{Ga}_{0.3} \mathrm{~N}$ :Si layer and $\mathrm{Al}_{\mathrm{y}} \mathrm{Ga}_{1-\mathrm{y}} \mathrm{N}$ QD are shown in Figure 1. Regarding $\mathrm{AlN}$ and $\mathrm{Al}_{0.7} \mathrm{Ga}_{0.3} \mathrm{~N}: \mathrm{Si}$, smooth surfaces are observed with root mean square (RMS) roughnesses of $1.3 \mathrm{~nm}$ and $0.3 \mathrm{~nm}$ for $\mathrm{AlN}$ and of $1.8 \mathrm{~nm}$ and $0.4 \mathrm{~nm}$ for $\mathrm{Al}_{0.7} \mathrm{Ga}_{0.3} \mathrm{~N}: \mathrm{Si}$ on $(10 \mathrm{x} 10) \mu \mathrm{m}^{2}$ and $(1 \mathrm{x} 1) \mu \mathrm{m}^{2}$ surface areas, respectively. Whereas no specific feature can be determined on the AlN BL surface, monoatomic surface steps oriented along $\langle 11 \overline{2} 0\rangle$ directions are found for the surfaces of $\mathrm{Al}_{0.7} \mathrm{Ga}_{0.3} \mathrm{~N}$ :Si. In the case of QD, the image presented in Figure 1(c) concerns $\mathrm{Al}_{\mathrm{y}} \mathrm{Ga}_{1-\mathrm{y}} \mathrm{N}$ QD with $\mathrm{y}=0.2$. From these AFM measurements, QD densities between $(3-6) \times 10^{11} \mathrm{~cm}^{-2}$ have been determined. These very high QD densities are attributed to the low growth 
temperature of $720^{\circ} \mathrm{C}$ used during the $\mathrm{Al}_{\mathrm{y}} \mathrm{Ga}_{1-\mathrm{y}} \mathrm{N}$ deposition and consequently the low diffusion length of $\mathrm{Ga}$ and $\mathrm{Al}$ adatoms. ${ }^{23,24}$ Concerning the QD size distribution, their lateral dimensions are typically ranging between 5 and $15 \mathrm{~nm}$ and their heights between 1.5 and $2.5 \mathrm{~nm}$.
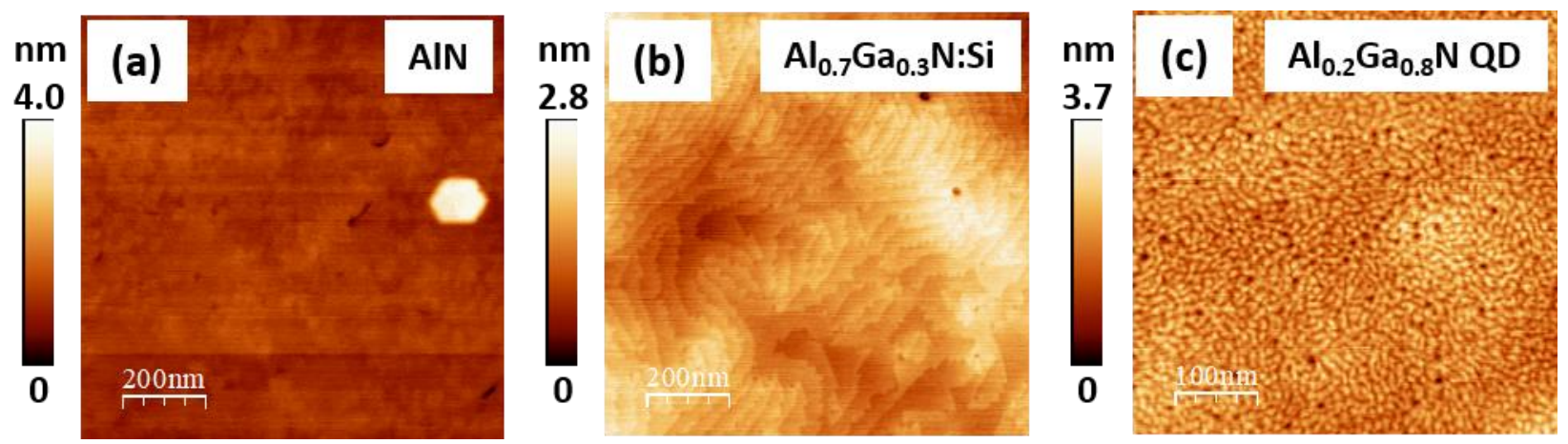

Figure 1. Atomic force microscopy images of: (a) AlN grown on c-plane sapphire; (b) $\mathrm{Si}$ doped $\mathrm{Al}_{0.7} \mathrm{Ga}_{0.3} \mathrm{~N}$ grown on $\mathrm{AlN}$;

(c) $\mathrm{Al}_{0.2} \mathrm{Ga} 0.8 \mathrm{~N}$ quantum dots (QD) grown on $\mathrm{Al}_{0.7} \mathrm{Ga} 0.3 \mathrm{~N}$.

PL measurements, using a frequency-doubled Ar laser excitation source at $244 \mathrm{~nm}$, of reference $\mathrm{Al}_{\mathrm{y}} \mathrm{Ga}_{1-\mathrm{y}} \mathrm{N}$ QD samples are shown in Figure 2 and compared with GaN QD. A strong shift in the UV range is obtained for the emission of $\mathrm{Al}_{\mathrm{y}} \mathrm{Ga}_{1-y} \mathrm{~N} \mathrm{QD}$ with an emission at shorter wavelengths as the $\mathrm{Al}$ concentration $\mathrm{y}$ is increased. Typically, $\mathrm{Al} \mathrm{l}_{0.1} \mathrm{Ga}_{0.9} \mathrm{~N} \mathrm{QD}$ emit in the 320-340 $\mathrm{nm}$ range, $\mathrm{Al}_{0.2} \mathrm{Ga}_{0.8} \mathrm{~N}$ QD between $310-330 \mathrm{~nm}, \mathrm{Al}_{0.3} \mathrm{Ga}_{0.7} \mathrm{~N}$ QD in the 290-320 $\mathrm{nm}$ range and $\mathrm{Al}_{0.4} \mathrm{Ga}_{0.6} \mathrm{~N}$ QD between 260-290 $\mathrm{nm}$. In the case of GaN QD, an emission in the near UV range between 370-400 $\mathrm{nm}$ and up to the visible blue range from 400 to $480 \mathrm{~nm}$ can be observed. ${ }^{5,24}$ Clearly, the influence of the internal electric field $\left(F_{\text {int }}\right)$ and the associated quantum confined Stark effect (QCSE) is enhanced in the case of GaN QD. This is a consequence of the larger lattice-mismatch with the $\mathrm{Al}_{\mathrm{x}} \mathrm{Ga}_{1-\mathrm{x}} \mathrm{N}$ cladding layer leading to an increase of $\mathrm{F}_{\text {int }}$ and a strong red-shift of the PL emission reaching much longer wavelengths compared to the GaN band gap one (i.e. $\lambda \approx 360 \mathrm{~nm}$ at room temperature). ${ }^{25}$ This characteristic also lead to a much larger PL peak broadening for GaN QD with full width at half maximum (FWHM) values that are typically in the order of 300-400 meV compared to $150-200 \mathrm{meV}$ in the case of $\mathrm{Al}_{\mathrm{y}} \mathrm{Ga}_{1-\mathrm{y}} \mathrm{N} \mathrm{QD}$. Yet, even in this latter case, the FWHM are still high and reflect alloy disorder during $\mathrm{Al}_{\mathrm{y}} \mathrm{Ga}_{1-\mathrm{y}} \mathrm{N}$ growth $^{26,27}$ along with QD sizes (heights) inhomogeneity, leading to variations in the QD band structure and consequently in the confinement energies and Stark effect. Time-resolved PL measurements at low temperature (8K) combined with temperature dependent PL measurements (between $8 \mathrm{~K}$ and $300 \mathrm{~K}$ ) have then been used to determine the QD internal quantum efficiencies (not shown): importantly, values above $10 \%$ have been obtained despite the very high TDD in the heterostructures (of the order of $5 \times 10^{10} \mathrm{~cm}^{-2}$ ). ${ }^{28}$

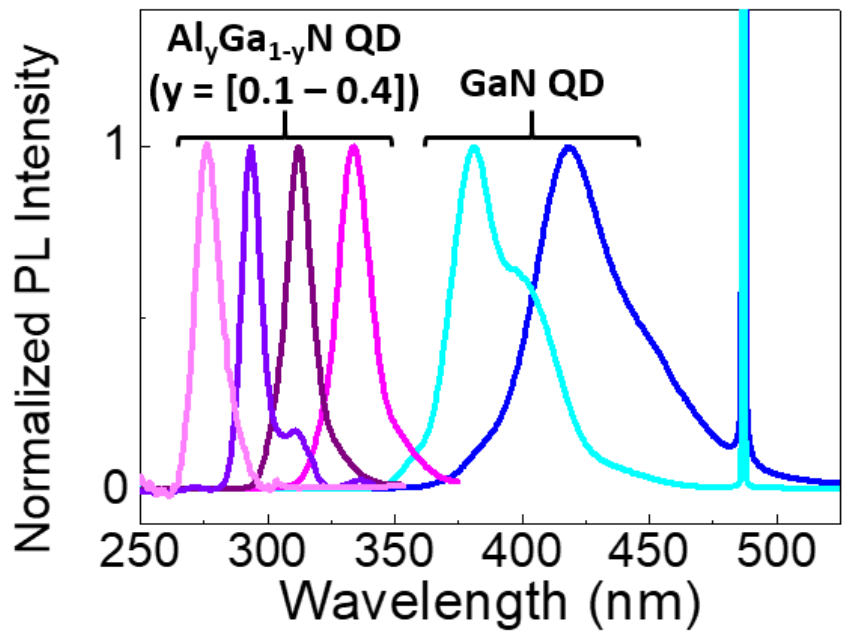

Figure 2. Photoluminescence spectra of $\mathrm{GaN}$ and $\mathrm{Al}_{\mathrm{y}} \mathrm{Ga}_{1-\mathrm{y}} \mathrm{N}$ quantum dots (QD), with y varying from 0.1 to 0.4 , grown on $\mathrm{Al}_{0.7} \mathrm{Ga} 0.3 \mathrm{~N}$ (0001) cladding layers. The sharp peak emission at $488 \mathrm{~nm}$ is the excitation laser (frequency-doubled $\mathrm{Ar}$ ) second order line emission. 
As presented below, LED structures designed with $\mathrm{Al}_{\mathrm{y}} \mathrm{Ga}_{1-\mathrm{y}} \mathrm{N}$ QD were then fabricated, processed and their electrooptical properties were investigated. A current - voltage characteristic is shown in Figure 3(b): a diode behavior is observed with an operating voltage of $13 \mathrm{~V}$ at $20 \mathrm{~mA}$ and a series resistance value of $50 \Omega$. In average, voltages between 10 and $15 \mathrm{~V}$ at $20 \mathrm{~mA}$ have been found in most of the LED and series resistances between 40 and $60 \Omega$. The EL spectra of three devices with different QD active regions are reported in Figure 3 (c). The EL spectra are all characterized by a single peak which originates from the QD emission: the maximum EL intensities are measured at 326, 306 and $269 \mathrm{~nm}$ for LED with QD (nominal) composition of $\mathrm{Al}_{0.1} \mathrm{Ga}_{0.9} \mathrm{~N}, \mathrm{Al}_{0.2} \mathrm{Ga}_{0.8} \mathrm{~N}$ and $\mathrm{Al}_{0.3} \mathrm{Ga}_{0.7} \mathrm{~N}$, respectively. As expected, the emission in the deeper UV range is found for QD with the higher Al concentration. Yet, the emission from the $\mathrm{Al}_{0.3} \mathrm{Ga}_{0.7} \mathrm{~N}$ QD is found at a much shorter wavelength then expected from the PL measurements performed on reference structures (as described in the previous paragraph). This point will be further discussed in the following section.
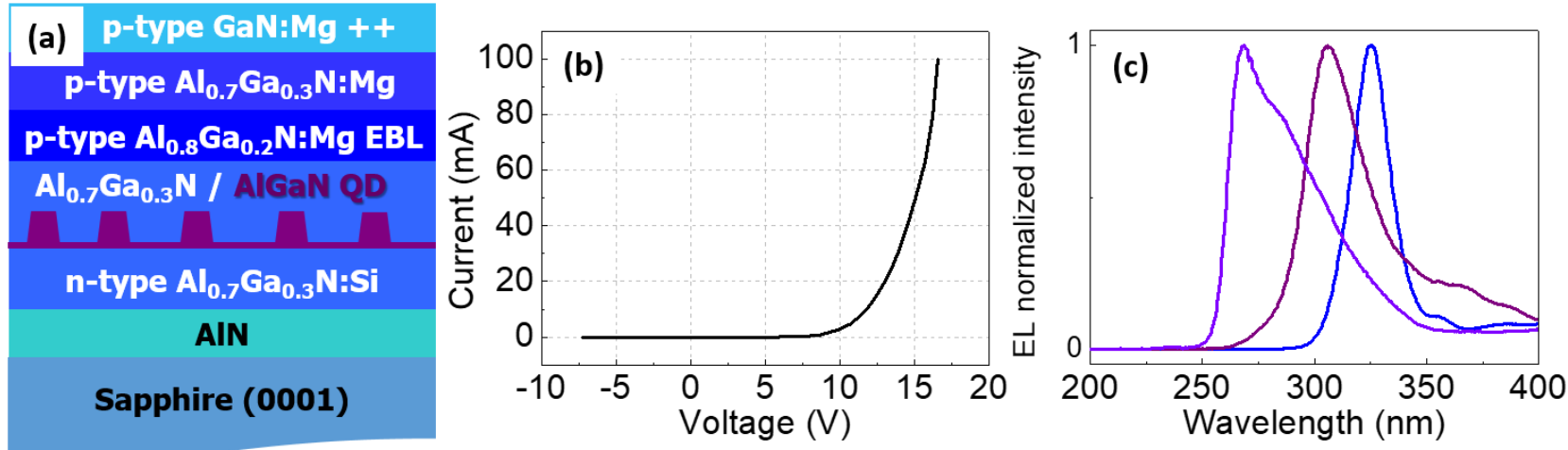

Figure 3. (a) Schematics of the $\mathrm{Al}_{\mathrm{y}} \mathrm{Ga}_{1-y \mathrm{~N}}$ quantum dots (QD) based light emitting diode (LED) structures grown on sapphire substrates. (b) Typical I-V characteristic of an $\mathrm{Al}_{0.7} \mathrm{Ga} 0.3 \mathrm{~N}$ based QD-LED showing a rectifying behavior with a voltage at around $13 \mathrm{~V}$ at $20 \mathrm{~mA}$. (c) Electroluminescence spectra (normalized intensity) at an input current of $20 \mathrm{~mA}$ of 3 different LED emitting in the UVA, UVB and UVC regions between $340 \mathrm{~nm}$ and $265 \mathrm{~nm}$

The main characteristics of our QD-based UV LED have been summarized in Figures 4 and 5 for the specific case of an active region made of $\mathrm{Al}_{0.2} \mathrm{Ga}_{0.8} \mathrm{~N}$ QD since similar trends are observed for all the devices as described elsewhere. ${ }^{11,21,22,24,29}$ The LED emission is strongly shifting into the UV at shorter wavelengths (from $349 \mathrm{~nm}$ down to $318 \mathrm{~nm}$ ) as the input current density (J) increases (Figure 4(a)) and at the same time the EL spectra FWHM is strongly reduced from $63 \mathrm{~nm}$ down to $31 \mathrm{~nm}$. In the measurements, the wavelength has been calculated as the arithmetic mean between the two wavelength values measured at full width at half maximum of each EL spectrum.
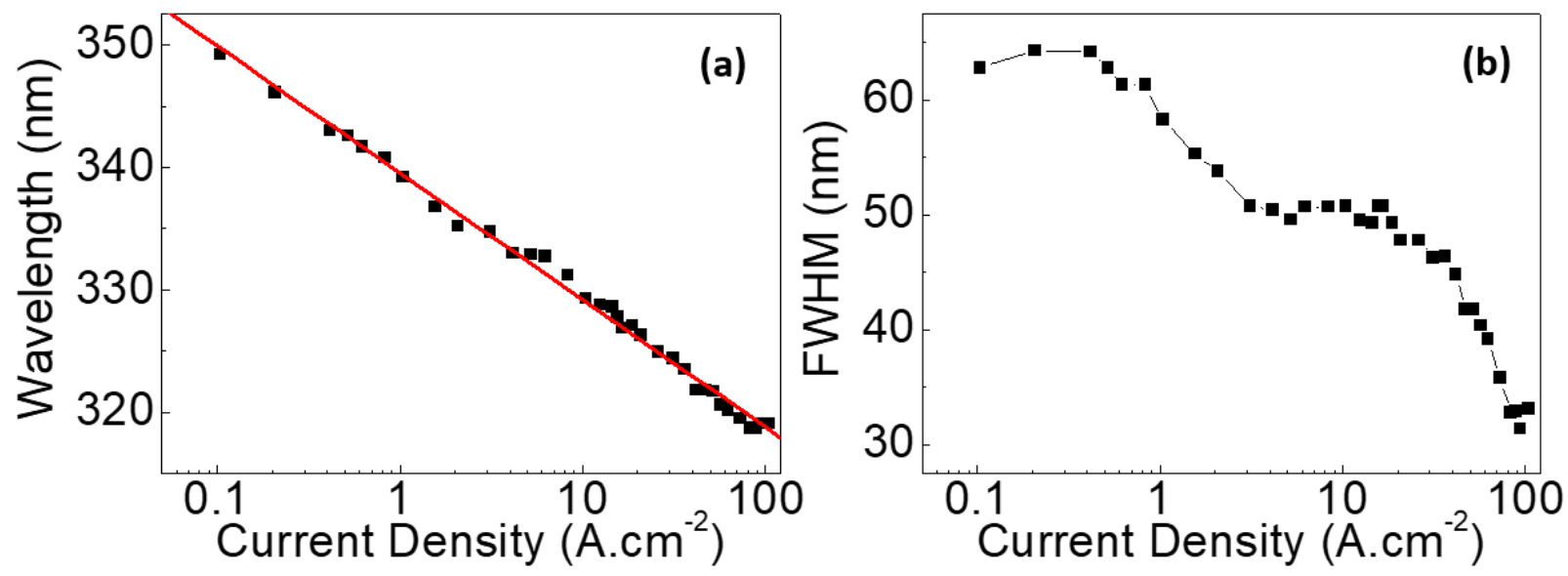

Figure 4. Al ${ }_{0.2} \mathrm{Ga} 0.8 \mathrm{~N}$ QD-based LED electroluminescence (EL) characteristics of: (a) the variation of the wavelength emission as a function of the current density. The black squares are experimental measurements and the line represents a linear fit of the wavelength variation; (b) the variation of the full width at half maximum (FWHM) of the EL peak as a function of the current density. 
The EQE and optical power of the LED as a function of $\mathrm{J}$ have been further investigated as shown in Figure 5. Maximum EQE close to $0.08 \%$ have been found at around $10 \mathrm{~A} . \mathrm{cm}^{-2}$. Below and above this maximum, the EQE is found to decrease progressively down to a minimum value of around $0.04 \%$ found at the minimum and maximum current densities of 0.1 and 100 A.cm ${ }^{-2}$, respectively. The decrease at high current densities is commonly observed in LED and known as the "efficiency droop" characterized by non radiative processes attributed to Auger recombination and electron leakage contribution. ${ }^{30}$ Regarding the optical power $\left(\mathrm{P}_{\mathrm{opt}}\right)$, values in the sub- $\mu \mathrm{W}$ range for current densities up to 0.5 A.cm ${ }^{-2}$ are found, then increasing at $55 \mu \mathrm{W}$ at $20 \mathrm{~A} . \mathrm{cm}^{-2}$, and reaching a maximum value of $155 \mu \mathrm{W}$ at $100 \mathrm{~A} . \mathrm{cm}^{-2}$. Yet, the optical power increase is not constant and varies as a function of $\mathbf{J}$ at a constant power $\mathrm{m}$. The value of $\mathrm{m}$ depends on

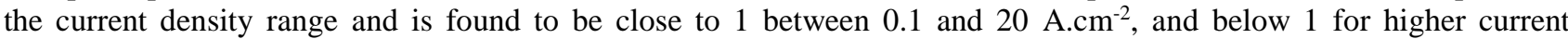
densities. A value of 0.75 is found for $J$ between 20 and $70 \mathrm{~A} . \mathrm{cm}^{-2}$ and for $\mathrm{J}$ above $70 \mathrm{~A} . \mathrm{cm}^{-2}$ it is found to be reduced to a value of 0.4 .
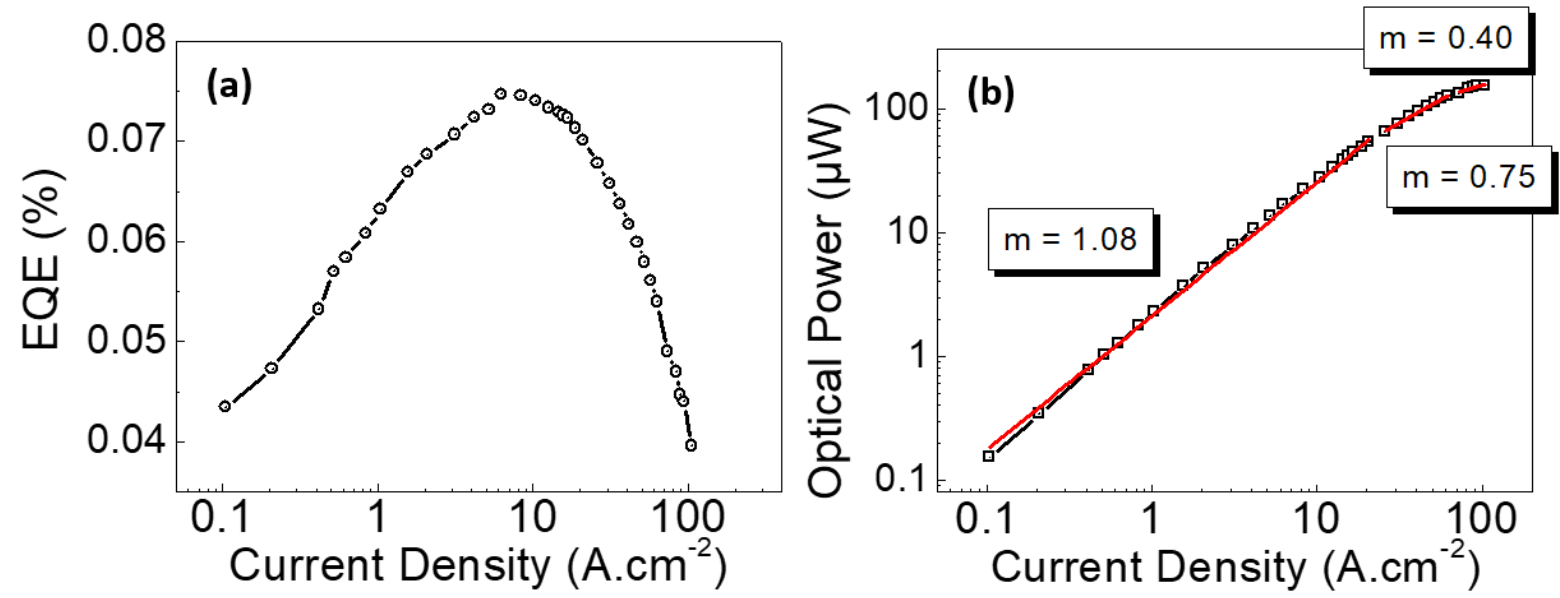

Figure 5. $\mathrm{Al}_{0.2} \mathrm{Ga}_{0.8} \mathrm{~N}$ QD-based LED characteristics of: (a) the variation of the external quantum efficiency (EQE) as a function of the current density $(\mathrm{J})$; (b) the variation of the optical power $\left(\mathrm{P}_{\mathrm{opt}}\right)$ as a function of $\mathrm{J}$. The segments represent fits of the variation of $\mathrm{P}_{\mathrm{opt}}$ with a power law $\mathrm{J}^{\mathrm{m}}$, where $\mathrm{m}$ is a coefficient determined by the fit.

\section{DISCUSSION}

The PL measurements clearly point out a significant influence of the internal electric field ( $\left.\mathrm{F}_{\text {int }}\right)$ and the QCSE on the QD emission. Due to the smaller $\mathrm{F}_{\text {int }}$ of $\mathrm{Al}_{\mathrm{y}} \mathrm{Ga}_{1-\mathrm{y}} \mathrm{N}$ QD (with $0.1 \leq \mathrm{y} \leq 0.4$ ), a reduction in the FWHM is observed (Figure 2) and the red-shift in the QD emission is also limited compared to the extreme case of GaN QD. However, when comparing the PL emission with the EL of QD-based LED (Figure 3(c)), an increase in the FWHM of the spectra is observed for the LED: 1) in the case of $\mathrm{Al}_{0.1} \mathrm{Ga}_{0.9} \mathrm{~N}$ QD active region, the PL FWHM is $\sim 16 \mathrm{~nm}(180 \mathrm{meV})$ while it is $~$ $21 \mathrm{~nm}(250 \mathrm{meV})$ in the case of the $\mathrm{EL} ; 2)$ for $\mathrm{Al}_{0.2} \mathrm{Ga}_{0.8} \mathrm{~N}$ QD, a value of $\sim 12 \mathrm{~nm}(150 \mathrm{meV})$ and $~ 30 \mathrm{~nm}(400 \mathrm{meV})$ for PL and EL FWHM, respectively; and finally 3) for $\mathrm{Al}_{0.3} \mathrm{Ga}_{0.7} \mathrm{~N}$ QD, a value of $\sim 8 \mathrm{~nm}(115 \mathrm{meV})$ for the PL FWHM and $\sim 34 \mathrm{~nm}(580 \mathrm{meV})$ for the EL FWHM are measured. Although the injection conditions (i.e. the carrier densities) in the QD differ between the LED and the reference PL structures for the measurements presented here, which has an inpact on the EL FWHM as shown in Figure 4(b), some tendencies can still be given: i) a decrease of the FWHM of the $\mathrm{PL}$ spectra is observed as the $\mathrm{Al}$ concentration in the $\mathrm{QD}$ increases which is attributed to the reduction of $\mathrm{F}_{\text {int }}$ as the $\mathrm{Al}$ concentration between the cladding layer $\left(\mathrm{Al}_{0.7} \mathrm{Ga}_{0.3} \mathrm{~N}\right)$ and the QD decreases; ii) an increase of the $\mathrm{FWHM}$ is systematically observed for LED compared to the reference sample. This characteristic is due to the multi-QD planes in the LED structure compared to the single QD plane in the reference one. It indicates that the QD composition and size (height) fluctuations increase when piling up the QD layers; iii) an opposite behavior is observed regarding the FWHM dependence on the QD Al concentration between the LED and the reference sample: the FWHM decreases in the latter case whereas it increases in the case of the LED. The FWHM reduction with the Al concentration increase for the reference samples can be seen as the direct consequence of the reduction of $F_{\text {int }}$ whereas its increase in the LED structures is due to an enhancement of the QD composition and size fluctuations as already discussed. It is worth noting that the FWHM broadening becomes extreme as the nominal Al concentration of the QD increases to 30\%, going from $250 \mathrm{meV}$ up to $580 \mathrm{meV}$ for $\mathrm{Al}_{0.1} \mathrm{Ga}_{0.9} \mathrm{~N}$ QD and $\mathrm{Al}_{0.3} \mathrm{Ga}_{0.7} \mathrm{~N}$ QD active regions, respectively. This result is attributed to an increase of the $\mathrm{Al}_{\mathrm{y}} \mathrm{Ga}_{1-\mathrm{y}} \mathrm{N}$ material intrinsic composition fluctuations as $\mathrm{Al}$ increases, ${ }^{26,27}$ adding to the broadening 
which comes for $\mathrm{F}_{\text {int. }}{ }^{22}$ In addition, the emission from the $\mathrm{Al}_{0.3} \mathrm{Ga}_{0.7} \mathrm{~N}$ QD (nominal composition) based LED is found at a much shorter wavelength then expected from the PL measurements performed on reference structures (cf. Figure 2 and Figure 3(c)), which gives another hint about the $\mathrm{Al}_{\mathrm{y}} \mathrm{Ga}_{1-\mathrm{y}} \mathrm{N}$ composition fluctuations for larger $\mathrm{Al}$ concentrations.

Looking now at the EL evolution as a function of the input current (density) presented in Figure 4(a), spectra for different current values have been extracted and are shown in Figure 6. Although the EL spectra shape is influenced by Fabry-Perot interferences resulting from the refractive index contrasts at the AlGaN/sapphire and the air/AlGaN interfaces and the maximum intensity peak wavelength remains fairly constant (between 318 and $324 \mathrm{~nm}$ ), a dependence of the EL as a function of the current is still observed: whereas at lower currents the broadening is mainly observed towards longer wavelengths (up to $380 \mathrm{~nm}$ ), an opposite feature is seen at larger currents with an increase of the EL at around 300-305 nm. This is a typical feature found in our LED: at lower J, carriers are preferentially injected in QD with lower $\mathrm{Al}$ concentrations (i.e. in deeper localization potentials) whereas a progressive injection into higher $\mathrm{Al}$ concentration $\mathrm{Al}_{\mathrm{y}} \mathrm{Ga}_{1-\mathrm{y}} \mathrm{N}$ QD occurs at larger $\mathrm{J}$ leading to an LED operation at shorter wavelengths. ${ }^{29}$

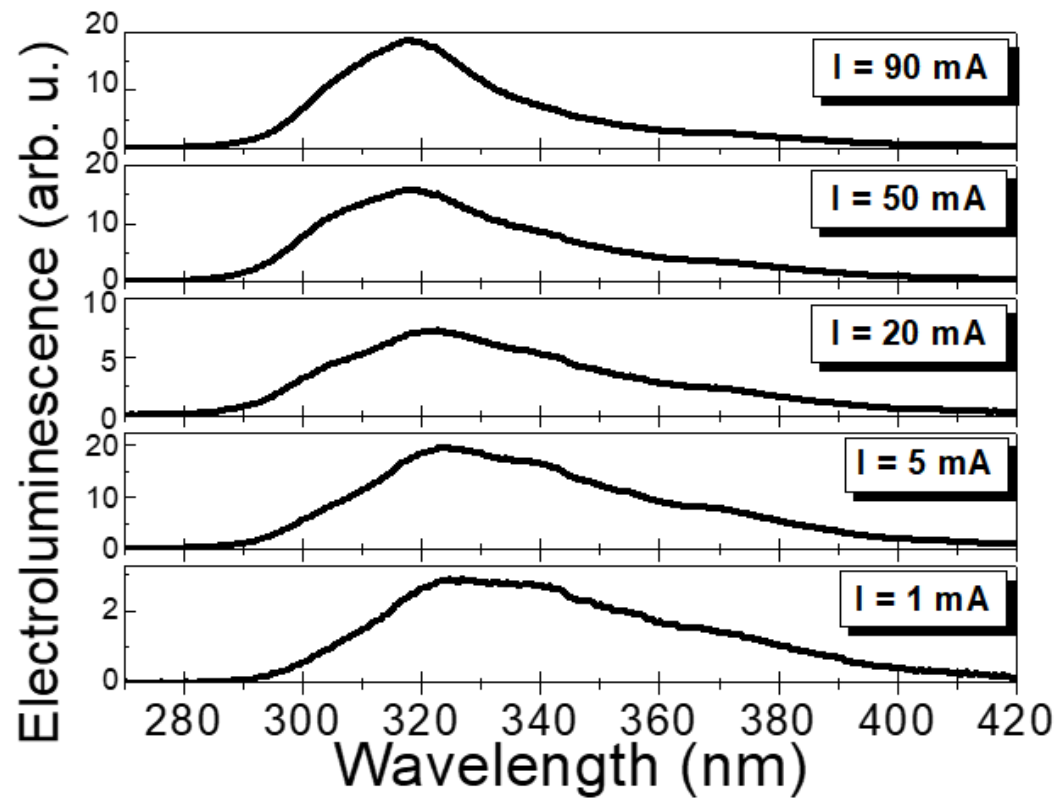

Figure 6. Electroluminescence spectra of a QD-based LED measured at different input currents (between 1 and $90 \mathrm{~mA}$ ).

The LED EQE and $\mathrm{P}_{\mathrm{opt}}$ are also dependent on the current density (Figure 5). The EQE is the product of the internal quantum efficiency (IQE), the injection efficiency (IE) and the extraction efficiency (EE). In our characterizations, the $\mathrm{EE}$ is constant and the variation of the EQE as a function of $\mathrm{J}$ point out a variation of the IQE and/or the IE. Combining the EQE measurements with the evolution of $\mathrm{P}_{\mathrm{opt}}$, it is then possible to conclude that: 1) at lower J, the IQE is constant

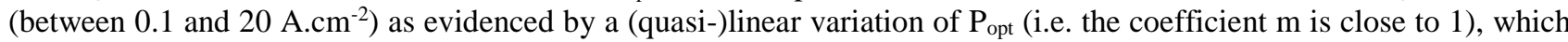
means that the IE increases; 2$)$ at higher $\mathrm{J}, \mathrm{m}$ is found below $1(\mathrm{~m} \sim 0.75)$ and $\mathrm{P}_{\text {out }}$ increases sub-linearly as a function of $\mathrm{J}$, leading to a decrease of the EQE; 3 ) a more pronounced decrease of $\mathrm{m}$ down to 0.4 is determined at largest $\mathrm{J}$, i.e. $\mathrm{P}_{\text {out }}$ starts to saturate, along with a strong drop in the EQE which is divided by 2 compared to its maximum value found at 8 A.cm ${ }^{-2}$. The reduction in the optical power increase above $20 \mathrm{~A} \cdot \mathrm{cm}^{-2}$ is related to thermal effects caused by a decrease of the (hole) injection efficiency into the QD active region (associated to Auger effects and/or electron overflow). ${ }^{30}$ Considering the typical operating voltages of the LED in the $10-15 \mathrm{~V}$ range, heating effect at the LED junction is seen as the main reason for the EQE decrease observed in our LED. Indeed, it the extreme case of highly resistive contacts and/or doped layers leading to even larger operating voltages as shown in the LED current - voltage measurements presented in Figure 7(a), the impact of the injection efficiency on the LED performances is even more obvious: in this example, the LED turn-on voltage is $11 \mathrm{~V}$ and it increases to $27 \mathrm{~V}$ at $20 \mathrm{~mA} . \mathrm{cm}^{-2}$. The optical power variation reported in Figure 7(b) is found to be linear as a function of the input current below $2 \mathrm{~A} . \mathrm{cm}^{-2}$ only and then increases sub-linearly. At $20 \mathrm{~A} . \mathrm{cm}^{-2}$ only, $\mathrm{P}_{\mathrm{opt}}$ saturates and even severely decreases at larger current densities leading to irreversible damages on the LED working operation. 

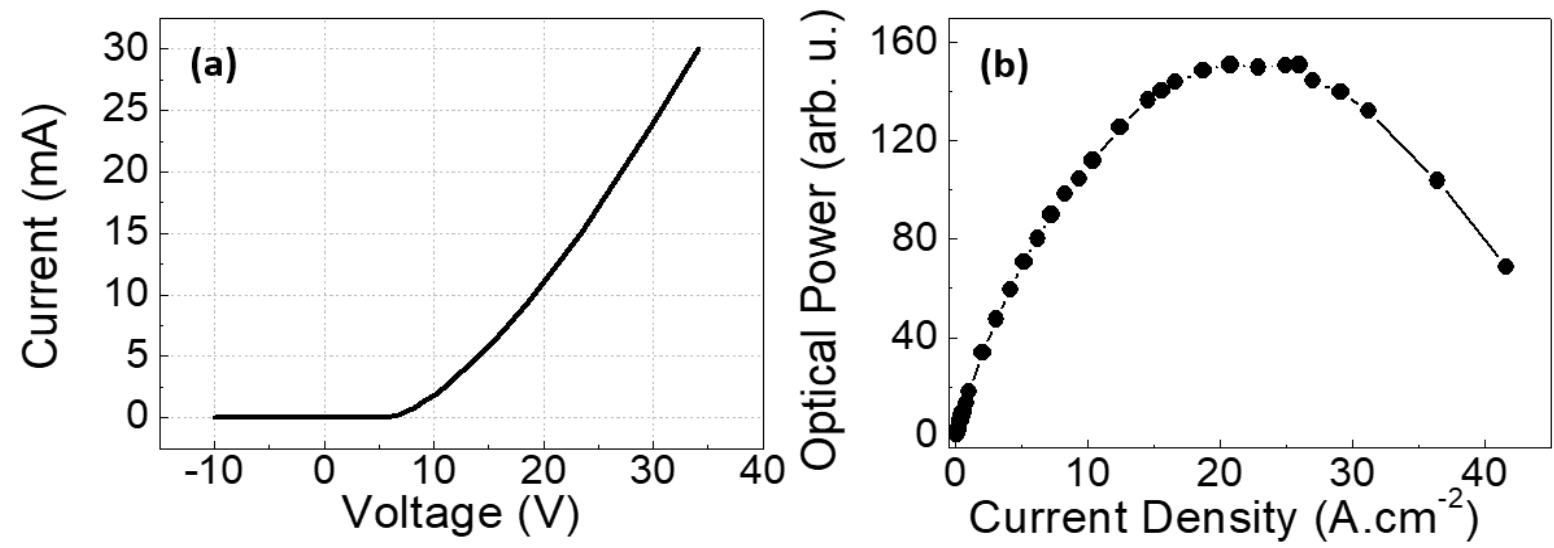

Figure 7. Performances of a QD-based LED with degraded electric properties: (a) I-V characteristic showing high voltages in operating conditions; (b) variation of the optical power $\left(\mathrm{P}_{\mathrm{opt}}\right)$ as a function of the current density. A strong decrease of $\mathrm{P}_{\mathrm{opt}}$ is observed for current densities above 20 A.cm².

\section{CONCLUSION}

In this study, the performances of $\mathrm{Al}_{\mathrm{y}} \mathrm{Ga}_{1-\mathrm{y}} \mathrm{N}$ QD-based UV LED emitting in a broad wavelength range, from $340 \mathrm{~nm}$ to $265 \mathrm{~nm}$, have been investigated and correlated with the QD structural and optical properties. In particular, important differences between the electroluminescence (EL) and the photoluminescence (PL) properties have been observed and attributed to an increase in the QD composition and size (height) inhomogeneities in the LED active regions due to the use of multiple QD planes compared to a single one for the reference samples used in the PL measurements. Concerning the LED characteristics, an analysis of the EQE and optical power dependence on the current density shows that a reduction in their values at higher $\mathrm{J}$ is mainly related to a decrease in the injection efficiency and associated to a heating effect. In addition, an important dependence on the EL wavelength as a function of $\mathbf{J}$ has been observed and attributed to injection into different QD populations related to a preferential carrier injection in deeper localization potentials (i.e. lower Al concentration and/or larger QD sizes (higher heights)) at lower J. To reduce the EL wavelength dependence on the current density as well as the EL peak broadening of the QD LED, non or semi polar orientations could be an attractive alternative, ${ }^{24}$ although improvements in the material crystalline quality of heterostructures grown on high index Miller planes are still required to reach the level of c-oriented heterostructures. In addition, an optimization of the surface morphology and/or cladding layer thickness between the $\mathrm{Al}_{\mathrm{y}} \mathrm{Ga}_{1-\mathrm{y}} \mathrm{N}$ QD planes could also lead to a specific and improved vertical organization and size uniformity of the nanostructures as shown in $\mathrm{GaN}$ and other semiconductor systems. ${ }^{31,32,33,34}$ To improve the injection efficiency, tunnel junctions for non-equilibrium hole injection appears to be an attractive approach ${ }^{35,36}$ and will be investigated in a near future.

\section{ACKNOWLEDGMENTS}

The authors would like to thank D. Lefebvre, S. Vézian, and B. Poulet for their help and input regarding the technical and scientific aspects of molecular beam epitaxy processes and maintenance. This research was partly funded by ANR Projects "NANOGANUV" (ANR-14-CE26-0025), "DUVET" (ANR-17-CE08-0024) and from GANEX (ANR-11LABX-0014). GANEX belongs to the publicly funded "Investissements d'Avenir" program managed by the French ANR agency. 


\section{REFERENCES}

[1] Arakawa, Y. and Sakaki, H., "Multidimensional Quantum Well Laser and Temperature Dependence of Its Threshold Current," Appl. Phys. Lett. 40, 939-941 (1982).

[2] Gérard, J.-M., Cabrol, O. and Sermage, B., "InAs quantum boxes: Highly efficient radiative traps for light emitting devices on Si," Appl. Phys. Lett. 68, 3123-3125 (1996).

[3] Damilano, B., Grandjean, N., Semond, F., Massies, J. and Leroux, M., "From visible to white light emission by GaN quantum dots on Si(111) substrate," Appl. Phys. Lett. 75, 962-964 (1999).

[4] Matta, S., Brault, J., Korytov, M., Phuong Vuong, T. Q., Chaix, C., Al Khalfioui, M., Vennéguès, P., Massies, J. and Gil, B., "Properties of AlN layers grown on c-sapphire substrate using ammonia assisted MBE, " J. Crystal Growth 499, 40-46 (2018).

[5] Huault, T., Brault, J., Natali, F., Damilano, B., Lefebvre, D., Nguyen, L., Leroux, M. and Massies, J., "Blue-light emission from GaN/Al ${ }_{0.5} \mathrm{Ga}_{0.5} \mathrm{~N}$ quantum dots," Appl. Phys. Lett. 92, 051911 (2008).

[6] Ban, K., Yamamoto, J.-i., Takeda, K., Ide, K., Iwaya, M. Takeuchi, T., Kamiyama, S., Akasaki, I. and Amano, H., "Internal Quantum Efficiency of Whole-Composition-Range AlGaN Multiquantum Wells," Appl. Phys. Express 4, 052101 (2011).

[7] Cho, Y. H., Kwack, H. S., Kwon, B. J., Barjon, J., Brault, J., Daudin, B., Mariette, H., and Le Si Dang, "Optical characteristics of hexagonal GaN self-assembled quantum dots: Strong influence of built-in electric field and carrier localization", Appl. Phys. Lett. 81, 4934 (2002).

[8] Kim, J. H., Kwon, B. J., Cho, Y. H., Huault, T., Leroux, M. and Brault, J. "Carrier transfer and recombination dynamics of a long-lived and visible range emission from multi-stacked GaN/AlGaN quantum dots," Appl. Phys. Lett. 97, 061905 (2010).

[9] Matta, S., Brault, J., Ngo, T. H., Damilano, B., Korytov, M., Vennéguès, P., Nemoz, M., Massies, J., Leroux, M. and Gil, B., "Influence of the heterostructure design on the optical properties of $\mathrm{GaN}$ and $\mathrm{Al}_{0.1} \mathrm{Ga}_{0.9} \mathrm{~N}$ quantum dots for ultraviolet emission," J. Appl. Phys. 122, 085706 (2017).

[10] Brault, J., Damilano, B., Courville, A., Leroux, M., Kahouli, A., Korytov, M., Vennéguès, P., Randazzo, G., Chenot, S., Vinter, B., De Mierry, P., Massies, J., Rosales, D., Bretagnon, T. and Gil, B., "Growth of GaN nanostructures with polar and semipolar orientations for the fabrication of UV LEDs," Proc. SPIE, 8986, 89860Z (2014).

[11] Brault, J., Rosales, D., Damilano, B., Leroux, M., Courville, A., Korytov, M., Chenot, S., Vennéguès, P., Vinter, B., de Mierry, P., Kahouli, A., Massies, J., Bretagnon, T. and B. Gil, "Polar and semipolar GaN/Al ${ }_{0.5} \mathrm{Ga}_{0.5} \mathrm{~N}$ nanostructures for UV light emitters," Semicond. Sci. Technol. 29, 084001 (2014).

[12] Matta, S., Brault, J., Ngo, T. H., Damilano, B., Leroux, M., Massies, J. and Gil, B., "Photoluminescence properties of (Al,Ga)N nanostructures grown on $\mathrm{Al}_{0.5} \mathrm{Ga}_{0.5} \mathrm{~N}$ (0001)," Superlattices \& Microstructures 114, 161 (2018).

[13] Schifani, G., Frisch, T., Brault, J., Vennéguès, P., Matta, S., Korytov, M., Damilano, B., Massies, J. and Aqua, J. N., "Wetting-Layer-Free AlGaN Quantum Dots for Ultraviolet Emitters," ACS Appl. Nano Mater. 3, 5, 4054 (2020).

[14] Brault, J., Huault, T., Natali, F., Damilano, B., Lefebvre, D., Leroux, M., Korytov, M., and Massies, J., "Tailoring the shape of $\mathrm{GaN} / \mathrm{Al}_{\mathrm{x}} \mathrm{Ga}_{1-\mathrm{x}} \mathrm{N}$ nanostructures to extend their luminescence in the visible range," J. Appl. Phys. 105, 033519 (2009).

[15] Kahouli, A., Kriouche, N., Brault, J., Damilano, B., Vennéguès, P., de Mierry, P., Leroux, M., Courville, A., Tottereau, O., and Massies, J., "GaN/Al ${ }_{0.5} \mathrm{Ga}_{0.5} \mathrm{~N}$ (11-22) semipolar nanostructures: A way to get high luminescence efficiency in the near ultraviolet range," J. Appl. Phys. 110, 084318 (2011).

[16] Cho, J. H., Lim, S. H., Jang, M. H., Lee, C., Yeo, H. S., Sim, Y. C., Kim, J. H., Matta, S., Alloing, B., Leroux, M., Park, S. H., Brault, J. and Cho, Y. H., "Broadband ultraviolet light source using GaN quantum dots formed on hexagonal truncated pyramid structures," Nanoscale Advances 2, 1449 (2020).

[17] Himwas, C., Songmuang, R., Le Si Dang, Bleuse, J., Rapenne, L., Sarigiannidou, E. and Monroy, E., "Thermal stability of the deep ultraviolet emission from AlGaN/AlN Stranski-Krastanov quantum dots," Appl. Phys. Lett. 101, 241914 (2012).

[18] Korytov, M., Benaissa, M., Brault, J., Huault, T., Neisius, T., and Vennéguès, P., "Effects of capping on GaN quantum dots deposited on $\mathrm{Al}_{0.5} \mathrm{Ga}_{0.5} \mathrm{~N}$ by molecular beam epitaxy, " Appl. Phys. Lett. 94, 143105 (2009). 
[19] Kneissl, M., "A Brief Review of III-Nitride UV Emitter Technologies and Their Applications," In III-Nitride Ultraviolet Emitters; Kneissl, M., Rass, J., Eds.; Publisher Springer International Publishing, Switzerland, Series in Materials Science Volume227, 1-25 (2016).

[20] for a review, see Amano, H. et al., "The 2020 UV emitter roadmap," J. Phys. D: Appl. Phys. 53 503001 (2020).

[21] Brault, J., Damilano, B., Kahouli, A., Chenot, S., Leroux, M., Vinter, B. and Massies, J., "Ultra-violet $\mathrm{GaN} / \mathrm{Al}_{0.5} \mathrm{Ga}_{0.5} \mathrm{~N}$ quantum dot based light emitting diodes," J. Cryst. Growth 363, 282 (2013).

[22] Brault, J., Al Khalfioui, M., Matta, S., Damilano, B., Leroux, M., Chenot, S., Korytov, M., Nkeck, J. E., Vennéguès, P.; Duboz, J. Y., Massies, J. and Gil, B., "UVA and UVB light emitting diodes with $\mathrm{Al}_{\mathrm{y}} \mathrm{Ga}_{1-\mathrm{y}} \mathrm{N}$ quantum dot active regions covering the 305-335 nm range," Semicond. Sci. Technol. 33, 075007 (2018).

[23] Brault, J., Matta, S., Ngo, T. H., Korytov, M., Rosales, D., Damilano, B., Leroux, M., Vennéguès, P., Al Khalfioui, M., Courville, A., Tottereau, O., Massies, J. and Gil, B., "Investigation of $\mathrm{Al}_{\mathrm{y}} \mathrm{Ga}_{1-\mathrm{y}} \mathrm{N} / \mathrm{Al}_{0.5} \mathrm{Ga}_{0.5} \mathrm{~N}$ quantum dot properties for the design of ultraviolet emitters, " Jpn. J. Appl. Phys. 55, 05FG06 (2016).

[24] Brault, J., Matta, S., Ngo, T. H., Rosales, D., Leroux, M., Damilano, B., Al Khalfioui, M., Tendille, F., Chenot, S., De Mierry, P., Massies, J. and Gil, B., "Ultraviolet Light Emitting Diodes using III-N Quantum Dots," Materials Science in Semiconductor Processing 55, 95 (2016).

[25] Leroux, M., Brault, J., Kahouli, A., Elmaghraoui, D., Damilano, B., de Mierry, P., Korytov, M., Kim, J. H. and Cho, Y. H., "Stark effect in ensembles of polar (0001) $\mathrm{Al}_{0.5} \mathrm{Ga}_{0.5} \mathrm{~N} / \mathrm{GaN}$ quantum dots and comparison with semipolar (11-22) ones," J. Appl. Phys. 116, 034308 (2014).

[26] Gao, M., Bradley, S. T., Cao, Y., Jena, D., Lin, Y., Ringel, S. A., Hwang, J., Schaff, W. J. and Brillson, L. J., "Compositional modulation and optical emission in AlGaN epitaxial films," J. Appl. Phys. 100, 103512 (2006).

[27] Fellmann, V., Jaffrennou, P., Sam-Giao, D., Gayral, B., Lorenz, K., Alves, E. and Daudin, B., "Ternary AlGaN Alloys with High Al Content and Enhanced Compositional HomogeneityGrown by Plasma-Assisted Molecular Beam Epitaxy," Jpn. J. Appl. Phys. 50, 031001 (2011).

[28] Brault, J., Matta, S., Ngo, T. H., Al Khalfioui, M., Valvin, P., Leroux, M., Damilano, B., Korytov, M., Brändli, V., Vennéguès, P., Massies, J. and Gil, B., "Internal quantum efficiencies of AlGaN quantum dots grown by molecular beam epitaxy and emitting in the UVA to UVC ranges," J. Appl. Phys. 126, 205701 (2019).

[29] Brault, J., Al Khalfioui, M., Matta, S., Ngo, T. H., Chenot, S., Leroux, M., Valvin, P. and Gil, B., "UVB LEDs Grown by Molecular Beam Epitaxy Using AlGaN Quantum Dots," Crystals 10, 1097 (2020).

[30] Piprek, J., "How to decide between competing efficiency droop models for GaN-based light-emitting diodes," Appl. Phys. Lett. 107, 031101 (2015).

[31] Brault, J., Tanaka, S., Sarigiannidou, E., Rouvière, J. L., Daudin, B., Feuillet, G. and Nakagawa, H., "Linear alignment of GaN quantum dots on AlN grown on vicinal SiC substrates," J. Appl. Phys. 93, 3108 (2003).

[32] Brault, J., Damilano, B., Vinter, B., Vennéguès, P., Leroux, M., Kahouli, A. and Massies, J., "AlGaN-Based Light Emitting Diodes Using Self-Assembled GaN Quantum Dots for Ultraviolet Emission," Jpn. J. Appl. Phys. 52, 08JG01 (2013).

[33] Stangl, J., Holý, V. and Bauer, G., "Structural properties of self-organized semiconductor nanostructures," Rev. Mod. Phys. 76, 725 (2004).

[34] Brault, J., Gendry, M., Grenet, G., Marty, O., Pitaval, M. and Hollinger, G., "Self-organization of stacked InAs / InAlAs quantum wires on InP(001)," Appl. Surf. Sci. 162/163, 584 (2000).

[35] Zhang, Y., Krishnamoorthy, S., Akyol, F., Bajaj, S., Allerman, A. A., Moseley, M. W., Armstrong, A. M. and Rajan S., "Tunnel-injected sub-260 nm ultraviolet light emitting diodes," Appl. Phys. Lett. 110, 201102 (2017).

[36] Fan Arcara, V., Damilano, B., Feuillet, G., Vézian, S., Ayadi, K., Chenot, S. and Duboz, J.-Y., "Ge doped GaN and $\mathrm{Al}_{0.5} \mathrm{Ga}_{0.5} \mathrm{~N}$-based tunnel junctions on top of visible and UV light emitting diodes, " J. Appl. Phys. 126, 224503 (2019). 